\title{
ANÁLISE DA EFICIÊNCIA DO USO DA ÁGUA NA FRUTICULTURA IRRIGADA DO VALE DO AÇU NO RIO GRANDE DO NORTE
}

\author{
Rosival Gomes de Brito ${ }^{1}$ \\ Zezineto Mendes de Oliveira ${ }^{2}$ \\ Joacir Rufino de Aquino ${ }^{3}$
}

Resumo: O objetivo deste artigo é analisar a eficiência do uso da água na fruticultura irrigada do Vale do $A c ̧ u / R N$ durante a grande seca que atingiu a microrregião no período de 2012-2015, em específico o caso dos produtores de manga e banana. Para tanto, foram usadas as técnicas de Data Envelopment Analysis (DEA), visando calcular os níveis de eficiência técnica e a eficiência de subvetor para medir a eficiência do uso da água. Os resultados da eficiência de subvetor apontam que, em média, $43 \%$ dos produtores de manga foram eficazes no uso da água. Os níveis de eficiência para os produtores de banana foram ainda mais baixos, alcançando apenas $28 \%$. Portanto, os padrões de uso da água na fruticultura irrigada do Vale do Açu podem ser otimizados mantendo-se o mesmo nível de produção, exigindo uma ação efetiva nesse sentido.

Palavras-chave: Água. Eficiência Técnica. Fruticultura irrigada.

\section{ANALYSIS OF EFFICIENCY OF WATER USE IN IRRIGATED FRUIT PRODUCTION OF AÇU VALLEY IN RIO GRANDE DO NORTE}

Abstract: The aim of this paper is analyze of water use in irrigated fruit growing in the Açu Valley / RN during the great drought was the microregion in the period 20122015, specifically the case of mango and banana producers. To this, they were used as Data Envelopment Analysis (DEA) techniques with the objective of improving the technique efficiency and sub-vector efficiency to measure water efficiency. The subocean evaluation results show that, on average, $43 \%$ of the hoses were efficiency in water use. Efficiency levels for banana growers were even higher, reaching $28 \%$. Therefore, the patterns of use of irrigated water in the Açu Valley can be optimized maintaining the same level of production, requiring a change in this direction.

Keywords: Water. Technical efficiency. Irrigated fruticulture.

\section{ANÁLISIS DE LA EFICIENCIA EN EL USO DEL AGUA EN LA CULTURA DE FRUTAS IRRIGADA DEL VALLE DE AÇU EN RIO GRANDE DO NORTE}

Resumen: El objetivo de este trabajo es analizar la eficiencia del uso del agua en el cultivo de frutas de regadío en el Valle de Açu / RN durante la gran sequía que alcanzó la microrregión en el período 2012-2015, específicamente el caso de los productores de mango y plátano. Con este fin, se utilizaron técnicas de Análisis de Envoltura de Datos (DEA) para calcular los niveles de eficiencia técnica y la eficiencia de sub-vectores para medir la eficiencia del uso del agua. Los resultados de eficiencia por debajo del vector indican que, en promedio, el $43 \%$ de los productores de mango fueron eficientes en el uso del agua. Los niveles de eficiencia para los productores de banano fueron aún más bajos, solo $28 \%$. Por lo tanto, los patrones de uso del agua en las frutas irrigadas que crecen en el Valle de Açu se

1 Universidade do Estado do Rio Grande do Norte, Mossoró, Brasil, rgb_brito@hotmail.com, https://orcid.org/0000-0002-6015-9641.

2 Universidade do Estado do Rio Grande do Norte, Departamento de Economia, Mossoró, Brasil, zezinetomendes@gmail.com, https://orcid.org/0000-0001-8170-1025.

3 Universidade do Estado do Rio Grande do Norte, Departamento de Economia, Assú, Brasil, joaciraquino@yahoo.com.br, http://orcid.org/0000-0003-0772-7141. 
pueden optimizar manteniendo el mismo nivel de producción, lo que requiere una acción efectiva en esta dirección.

Palabras clave: Agua. Eficiencia técnica. Fruticultura de regadio.

\section{INTRODUÇÃO}

A água é um recurso natural precioso e essencial para a existência da vida na Terra. Entretanto, ao longo dos anos vem percebendo-se um aumento do seu uso inadequado e, em algumas regiões do planeta, sua oferta limitada vem tornando-se realidade. Isso tem acontecido principalmente nos países situados na África, na Ásia, na América Latina e no Oriente Médio, territórios que apresentam pontos críticos de escassez de água (UNESCO, 2016).

No Brasil a escassez (carência) hídrica já é notória e traz diversos transtornos para algumas regiões, em maior proporção no Nordeste. A Agência Nacional de Águas (ANA) tem alertado sobre o aumento dos conflitos pelo uso da água na região, que tem a seca como uma das principais causas da falta de água. Dentre os eventos de seca identificados no país de 2013 a 2016, o Nordeste lidera com 83\% dos 5.154 registros, prejudicando o abastecimento público e a oferta de água para as atividades econômicas (ANA, 2017).

O Nordeste é a terceira maior região do Brasil, com uma área de 1.554.257 $\mathrm{km}^{2}$, e a segunda mais populosa, com aproximadamente 53 milhões de habitantes (IBGE, 2018). Para fazer frente às secas, a agricultura irrigada foi incentivada como alternativa importante para produção regular de alimentos, além de proporcionar o desenvolvimento com a geração de emprego e renda na região.

A presença do Estado, por meio de políticas públicas implantadas pela Superintendência de Desenvolvimento do Nordeste (SUDENE) e pelo Departamento Nacional de Obras Contra as Secas (DNOCS), foi de fundamental importância para o desenvolvimento e modernização da agricultura irrigada nordestina (ALVES; AQUINO; SILVA FILHO, 2018), destacando-se o polo irrigado do Vale do São Francisco e o polo Açu/Mossoró.

Paralelo ao crescimento da agricultura irrigada e seus incentivos, surgem os conflitos pela utilização do uso da água para fins econômicos e para o abastecimento humano. Tais disputas se agravam com os longos períodos de seca. De 2012 a 2016, o Rio Grande do Norte (RN) foi palco de uma longa estiagem, afetando os volumes de água dos seus principais reservatórios (FRANÇA; MORENO, 2017; SOUZA; AQUINO, 2018). O maior reservatório do estado, a 
Barragem Armando Ribeiro Gonçalves, atingiu a marca de 20,84\% de sua capacidade em 2015 (SEMARH, 2015).

Por conta da Grande Seca, o Vale do Açu, onde é localizada a Barragem Armando Ribeiro Gonçalves, passou por uma série de restrições no uso da água. No ano de 2015, a ANA estabeleceu cortes e proibições do uso da água para irrigação no leito do rio Piranhas-Açu, afetando 1,5 mil irrigantes. No mesmo ano, o Instituto Gestor das Águas do Rio Grande do Norte (IGARN) suspendeu o uso da água do canal Pataxó por denúncias de desperdícios e mau uso desse recurso na fruticultura regional (MARTINS; JULIÃO, 2015).

Mas será que a fruticultura irrigada no Vale do Açu é mesmo desperdiçadora de água? Qual o nível de eficiência (ou ineficiência) dos produtores no que se refere ao uso desse recurso natural escasso?

Diante destes questionamentos, visando contribuir com o debate sobre 0 tema, o objetivo deste artigo consiste em analisar a eficiência do uso dos recursos hídricos nos processos de irrigação no Vale do Açu/RN no período de 2012 a 2015. Especificamente, pretende-se identificar as principais culturas praticadas na área estudada e investigar se os sistemas de irrigação utilizados pelos produtores apresentam eficiência ou não no uso racional da água.

A estrutura do trabalho está dividida em mais quatro seções, além desta breve Introdução. Na segunda seção, são apresentados alguns aspectos gerais das técnicas de Data Envelopment Analysis (DEA) para a análise da eficiência e sua aplicação na agricultura. Já na terceira seção, é exposta a metodologia do estudo, como também são descritas a forma como se deu a coleta de dados e as especificações do modelo DEA. Na quarta seção foram analisados e discutidos os resultados dos modelos estatísticos aplicados para as culturas de manga e da banana. Na quinta última seção, são tecidas as considerações finais, bem como algumas sugestões para o desenvolvimento de novos estudos.

\section{REVISÃO DA LITERATURA}

Evolução e importância do modelo Data Envelopment Analysis (DEA) para o estudo da eficiência produtiva

A proposta deste estudo é analisar a eficiência do uso da água na produção da fruticultura irrigada. Para isso, deve-se entender os conceitos de eficiência e da função de produção, os quais relacionam as quantidades de entradas para gerar uma ou mais saídas. A eficiência é um conceito utilizado para mensurar o 
comportamento de uma Decision Making Units (DMU, Unidades de Tomada de Decisão), quando esta relaciona as quantidades ótimas entre as entradas (inputs) e as saídas (outputs) de um processo produtivo (CHARNES; COOPER; RHODES, 1978).

O desempenho de uma firma está relacionado às escolhas ótimas. E uma estimativa da eficiência de uma empresa, além de colaborar para fortalecer as tomadas de decisões, identifica o potencial máximo de produção e auxilia na formação de estratégias táticas e no planejamento da DMU (TUPY; YAMAGUCHI, 1998). Na literatura atual, dois grandes grupos destacam-se na análise das técnicas de eficiência: as técnicas paramétricas e as não-paramétricas.

As técnicas paramétricas buscam calcular a eficiência por meio da obtenção de uma função de produção, que correlaciona os inputs e outputs de uma empresa, podendo ser analisada por duas óticas: estocásticas e determinísticas. Já as técnicas não-paramétricas dispensam a estimativa de uma função de produção para medir a eficiência, fazendo isso por meio de uma construção de fronteira ou por comparações entre DMUs. Assim, calcula-se a eficiência a partir da construção empírica de uma fronteira de eficiência, podendo ser construídas por segmentos lineares a partir das observações de uma amostra das reais DMUs eficientes e de DMUs virtuais (MARIANO, 2008).

As aplicações das técnicas não-paramétricas tomam maior intensidade com o trabalho de M. J. Farrell. Em seu paper seminal sobre eficiência, o referido autor explica que a fronteira de eficiência de uma DMU poderia ser representada por uma isoquanta. Essa isoquanta é construída por segmentos lineares das combinações de insumos utilizados pelas DMUs eficientes (FARRELL, 1957). A partir desse estudo pioneiro, criou-se espaço para diversas discussões e aperfeiçoamentos das aplicações de métodos e técnicas sobre eficiência.

Nos anos 1970, A. W. Charnes, W. W. Cooper e E. Rhodes aplicam técnicas de programação matemática e generalizam a ideia de M. J. Farrell. Com isso, conseguiram mensurar a eficiência técnica para múltiplas entradas e múltiplas saídas. Essa técnica ficou conhecida como Análise Envoltória de Dados (Data Envelopment Analysis - DEA) e recebeu a denominação de CCR, que são as iniciais dos nomes dos autores. O referido modelo trabalha com retornos constantes de escala (Constant Returns to Scale - CRS), isto é, quando ocorre uma variação da utilização de todos os insumos, verifica-se uma variação exatamente igual no nível 
de produção. Tal relação faz com que a fronteira de eficiência do modelo CRS seja no formato de uma reta (CHARNES; COOPER; RHODES, 1978).

Já em 1984, Rajiv D. Banker, Abraham Charnes e William Wager Cooper complementam o modelo desenvolvido por Charnes, Cooper e Rhodes (1978) e incorporam na sua estrutura os Retornos Variáveis de Escala (Variant Returns to Scale - VRS). Segundo eles, quando ocorre uma variação proporcional em todos os insumos isso pode causar um impacto no nível de produção de magnitude maior, igual ou menor do que a variação nos insumos. Esse modelo ficou conhecido como BCC (Banker, Charnes e Cooper), que também leva as iniciais dos seus autores. A fronteira do modelo BCC é formada por conjuntos de retas de ângulos diferentes, o que implica numa fronteira linear por parte (BANKER; CHARNES; COOPER, 1984).

De maneira geral, a aplicação do modelo DEA e seus aprimoramentos possibilita avaliar os desempenhos de diversas unidades econômicas (cidades, regiões, países, instituições públicas ou privadas, empresas, etc.) que utilizam diferentes tipos de insumos (inputs) para produzir, auxiliando os gestores e administradores nas tomadas de decisões. $\mathrm{Na}$ agricultura, especificamente, os estudos vêm sendo aperfeiçoados e o modelo DEA tem sido utilizado para medir a eficiência técnica em diversos segmentos, como, por exemplo, na produção irrigada.

\section{Aplicação do modelo DEA nos estudos sobre eficiência técnica na agricultura}

A aplicação do modelo DEA para mensurar a eficiência de produtores rurais é considerado algo novo nos estudos de Economia Rural/Agrícola. Essa técnica de análise tem contribuído para o melhoramento da tomada de decisões, bem como vem despertando novos olhares para o aprimoramento e aplicação desses modelos na área. Algumas pesquisas vêm sendo desenvolvidas e têm como método de avaliação a aplicação do DEA para medir a eficiência no setor primário. Vários estudos, como os de Wadud e White (2000), De Koeijer et al. (2002), Coelli, Rahman e Thirtle (2002) e Dhungana, Nuthall e Nartea (2004) analisaram a eficiência produtiva do setor agrícola, sendo que a maioria deles é voltada para monoculturas como o arroz.

No caso específico da utilização da água na irrigação, pode-se citar o trabalho de Speelman et al. (2008), que aplicaram o modelo DEA e de eficiência de subvetor para medir a eficiência de uso da água no sistema irrigado de uma Província no Noroeste da África do Sul. Esse estudo utilizou a técnica que se originou do trabalho seminal de Farrell (1957) para encontrar o indicador de eficiência do uso da água 
entre pequenos produtores do município de Zeerust. Já Chebil, Frija e Abdelkafi (2012) usam o modelo DEA não paramétrico para medir a eficiência de uso da água de irrigação, buscando verificar as possíveis reduções de custos de irrigação e os principais fatores que causam variações na eficiência do uso da água entre uma amostra de fazendas irrigadas na Tunísia.

No Brasil, em específico no Nordeste, alguns estudos dessa natureza também vêm sendo realizados no setor da fruticultura irrigada. Nesse contexto, pode-se destacar o trabalho de Mariano e Sampaio (2002), que analisa a eficiência técnica dos produtores de um perímetro irrigado no Vale do São Francisco. Na mesma linha, Mariano e Pinheiro (2009) usam o modelo DEA para medir a eficiência técnica dos agricultores familiares do Projeto de Irrigação do Baixo Açu/RN. Já Pinheiro (2010) desenvolveu uma análise da eficiência dos custos dos pequenos produtores do mesmo projeto de irrigação localizado no semiárido potiguar.

Nesse sentido, os estudos citados buscaram analisar a eficiência técnica na fruticultura irrigada nordestina, avaliando o desempenho dos produtores e os determinantes dessa eficiência. Dada a importância dessas pesquisas, o presente trabalho direciona sua ênfase mais especificamente ao uso da água como principal insumo para a agricultura irrigada. Assim, este artigo visa preencher uma lacuna e contribuir para ampliar a compreensão do tema. Para tanto, foi utilizado o modelo DEA e da eficiência de subvetor para medir o desempenho do uso da água na irrigação da microrregião do Vale do Açu/RN. Essa avaliação permitirá verificar se os irrigantes da área estão utilizando de forma eficiente ou não esse recurso natural.

\section{METODOLOGIA}

\section{Breve caracterização da área de estudo}

A microrregião do Vale do Açu é situada no estado do Rio Grande do Norte $(\mathrm{RN})$, fazendo parte da região Semiárida do Nordeste brasileiro. Em termos políticoadministrativos, divide-se em nove municípios: Assú, Alto do Rodrigues, Carnaubais, Ipanguaçu, Itajá, Jucurutu, Pendências, Porto do Mangue e São Rafael (Figura 1). Com uma área total de $4.781,12 \mathrm{~km}^{2}$, ocupa $9,0 \%$ do território norte-rio-grandense (IBGE, 2018). 
Figura 1 - Localização geográfica da microrregião do Vale do Açu/RN

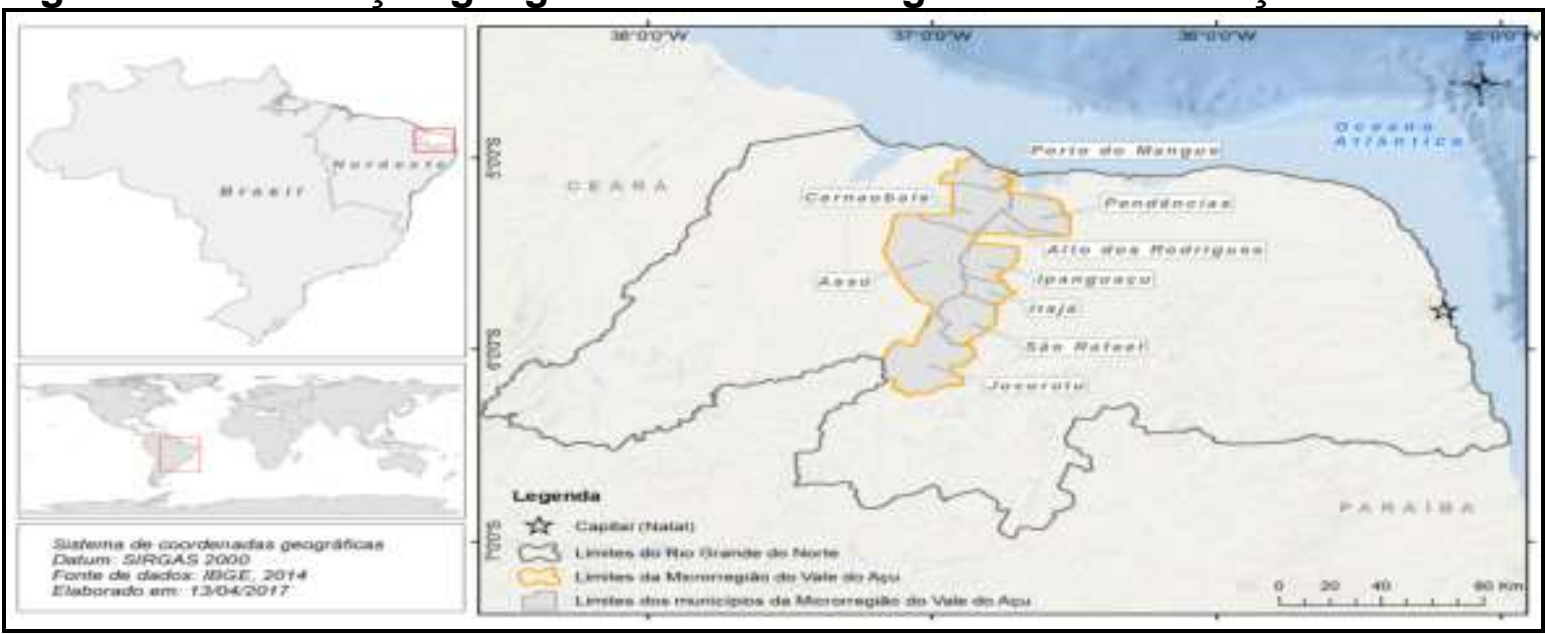

Fonte: Alves, Aquino e Silva Filho (2018, p. 44).

A fruticultura irrigada no Vale do Açu começou de forma tímida por volta de 1950 e ganha força com a construção da Barragem Armando Ribeiro Gonçalves (com capacidade para armazenar 2,4 bilhões de $\mathrm{m}^{3}$ de água) no início dos anos 1980 (ALBANO; SÁ, 2009). Posteriormente, grandes projetos de irrigação foram implantados com o apoio e incentivos governamentais. Dentre estes projetos, podemos citar o Projeto Baixo Açu, o qual atendeu em sua primeira fase 161 pequenos produtores, 6 técnicos agrícolas, 8 engenheiros agrônomos, 10 empresas e 1 empresa de pesquisa, totalizando 186 beneficiados (NUNES; ORTEGA; GODEIRO, 2007).

Paralelo à implantação do Projeto Baixo Açu, grupos de investidores nacionais e estrangeiros atraídos pelos incentivos fiscais oferecidos pelo Estado ocuparam grandes extensões de terras. Assim, empresas como a multinacional Del Monte Fresh Produce e o Grupo Vicunha implantaram seus projetos de irrigação na área visando usufruir do potencial produtivo regional, dos solos férteis e da mão de obra local barata.

Com a chegada das grandes empresas, a fruticultura irrigada do Vale do Açu ganha destaque no mercado nacional e internacional. Em 2006, os municípios açuenses somavam uma área irrigada de 8.307 hectares (IBGE, 2012). Entre as principais culturas irrigadas destacam-se a manga e, especialmente, a banana. Os municípios com maiores produções dessas frutas são: Alto do Rodrigues, Ipanguaçu e Assú. Segundo dados da PAM/IBGE (2018), somados, eles produziram no ano de 2015 um total de 98.232 toneladas dessas frutas, o que correspondeu a $89 \%$ da produção na microrregião. 
As plantações de banana e manga são cultivadas tanto por pequenos quanto por médios e grandes produtores. No tocante às propriedades, em sua maioria, os cultivos de banana não ultrapassam a média de 10 hectares, sendo comumente conduzidas por agricultores familiares (GUERRA, 2012). Ambas as culturas têm destaque no mercado interno e externo. No mercado interno essas frutas são comercializadas na sua maioria por atravessadores e são distribuídas para os comércios locais, como supermercados e feiras livres, como também são fornecidas para as Centrais Estaduais de Abastecimento (CEASAs), indústrias de fabricação de doces e de polpa de frutas.

Para o cultivo irrigado desenvolvido na região, os produtores utilizam equipamentos tecnológicos disponíveis no mercado interno (GUERRA, 2012). Os principais métodos de irrigação utilizados são: irrigação de superfície (inundação e sulcos), irrigação por aspersão (convencional, canhão), irrigação por pivô central e irrigação localizada (gotejamento, micro aspersão). No preparo do solo para o plantio, os produtores utilizam maquinários (tratores) para o corte de terras e usam fertilizantes químicos, que são comprados em lojas de produtos agrícolas da região.

\section{Amostra e coleta de dados}

Os dados utilizados no presente estudo foram coletados a partir de questionários aplicados juntos a pequenos, médios e grandes produtores da fruticultura irrigada do Vale do Açu/RN. Em 2006, a microrregião contabilizava 924 estabelecimentos irrigados. Desse total, 604 (65\%) estavam concentrados nos municípios Assú, Alto do Rodrigues e Ipanguaçu, sendo que 365 eram estabelecimentos irrigados de produção de manga e banana (IBGE, 2012).

Diante do quantitativo de empreendimentos irrigados instalados na região, decidiu-se delimitar uma amostra do universo de produtores de manga e banana. Para determinar o tamanho da amostra, adotou-se a seguinte fórmula indicada por Gil (2008):

$$
n=\frac{N \cdot Z^{2} \cdot p(1-p)}{Z^{2} \cdot p \cdot(1-p)+e^{2} \cdot(N-1)}
$$


onde, $n=$ Tamanho da amostra; $N=$ Tamanho da população; $Z$ = Variável normal padronizada associada ao nível de confiança; $p=$ Verdadeira probabilidade do evento; $e^{2}=$ Erro máximo permitido.

Considerando o tamanho da população $(\mathrm{N}=365)$, o nível de confiança de 95\%, uma estimativa de erro de $5 \%$ e partindo do pressuposto de que o número de produtores eficientes seja aproximadamente de 15\% com base no estudo realizado na região por Mariano e Pinheiro (2009), obteve-se uma amostra de 128 fruticultores, sendo 30 (23\%) produtores de manga e 98 (77\%) de banana.

Definido o tamanho da amostra, os 128 questionários foram aplicados nos meses de setembro e outubro de 2017, tendo como referência os meses de janeiro de 2012 a dezembro de 2015, abrangendo a período de grande seca que atingiu a região (SOUZA; AQUINO, 2018). Os questionários serviram para obter informações sobre as características dos sistemas de irrigação, onde foram identificadas as variáveis de entradas (inputs) e saída (outputs) da produção. Para os inputs, as variáveis observadas foram: área de plantio medida em hectares, quantidade de água utilizada $\left(\mathrm{m}^{3}\right)$, mão de obra (homem/dias), mecanização (valor monetário), fertilizantes (valor monetário) e pesticidas (valor monetário). Já para os outputs foram coletadas informações das quantidades produzidas em toneladas e os respectivos valores monetários.

Visando alcançar os objetivos propostos na pesquisa, após a coleta dos dados, foi aplicado o método de Análise Envoltória de Dados (DEA), para medir a eficiência técnica dos produtores da fruticultura irrigada do Vale do Açu/RN. Como na agricultura não controlamos as saídas, o modelo que mais se adéqua é o BCC, mais conhecido na literatura como Retornos Variáveis de Escala (Varint Returns to Scale -VRS). Já para mensurar a eficiência do uso da água utilizada na irrigação, foi aplicado o modelo de eficiência de subvetor. Ambos os modelos serão detalhados a segui.

\section{Descrição do modelo Data Envelopment Enalysis (DEA) utilizado na análise dos dados coletados}

Como foi visto anteriormente, o DEA é uma ferramenta usada para medir a eficiência relativa de uma unidade tomadora de decisão individual, dentro do conjunto de unidades em análise. Trata-se de uma técnica baseada em 
programação linear, utilizada para resolver os problemas de otimização (JUBRAN, 2006), em que é construída uma fronteira de eficiência a partir das unidades produtivas mais eficientes e posteriormente são dadas as medidas de eficiência das demais unidades em análise.

Essa técnica DEA foi desenvolvida por Charnes, Cooper e Rhodes (1978), que analisaram o quanto o programa social "Follow Through" era efetivo no melhoramento educacional das escolas que aderiram a esse programa. Em seu modelo inicial, os referidos autores assumiram a suposição de retorno constante de escala, ficando conhecido na literatura como modelo CCR ou CRS, que é derivado da sigla em inglês (Constant Returns to Scale - CRS). Neste modelo, eles consideraram que $k$ DMUs usavam $m$ inputs $x_{i j}(i=1,2,3, \ldots \ldots m)$ para gerar $s$ outputs, $y_{i j}(i=1,2,3, \ldots \ldots . s)$, sendo $v e u$ os pesos dados para cada input e output, respectivamente.

Para encontrar os escores de eficiência, foi resolvido o problema de maximização, como mostra a equação (2):

$$
\begin{gathered}
\operatorname{MaxP}_{0}=\frac{\sum_{r=1}^{s} u_{r} \cdot y_{r 0}}{\sum_{i=1}^{m} v_{i} \cdot x_{i 0}} \\
\text { sujeito a } \\
\frac{\sum_{r=1}^{n} u_{i} \cdot y_{r j}}{\sum_{i=1}^{m} v_{i} \cdot x_{i j}} \\
v_{i}, u_{i} \geq 0 ; j=1, \ldots \ldots, n ; r=1, \ldots \ldots s ; i=1, \ldots . . m .
\end{gathered}
$$

Linearizando as equações, tem-se:

$$
\begin{gathered}
\operatorname{Max}_{0}=\sum_{r=1}^{s} u_{r} \cdot y_{r 0} \\
\text { sujeito a } \\
\sum_{i=1}^{m} v_{i}, x_{i 0}=1 \\
\sum_{r=1}^{n} u_{i} \cdot y_{r j}-\sum_{i=1}^{m} v_{i}, x_{i j} \leq 0,
\end{gathered}
$$

onde $x_{i j}$ e $y_{r j}$ são as entradas e saídas das DMUs e $v_{i}, u_{i} \geq 0$ são os pesos das variáveis a serem determinadas pela solução deste problema.

Já Banker, Charnes e Cooper (1984), conforme também foi apresentado no início deste artigo, implementaram o modelo de Charnes, Cooper e Rhodes (1978) incorporando a suposição de retornos variáveis de escala, ficando conhecido na literatura como modelo BCC ou de Retornos Variáveis de Escala (Variable Scale Returns -VRS). Tal modelo substitui o axioma da proporcionalidade pelo axioma da convexidade, permitindo que as DMUs que operam com baixos valores de inputs 
tenham retornos crescentes de escala e as que operam com altos valores tenham retornos decrescentes de escala.

$\mathrm{Na}$ expressão matemática, o axioma de convexidade da fronteira equivale a uma restrição adicional no modelo $\mathrm{BCC}$, isto é, um acréscimo de uma variável W que possibilita ao modelo fornecer os retornos variáveis de escala. Assim, este pode ser orientado aos inputs ou outputs, como é mostrado nas expressões (4) e (5):

$$
\begin{gathered}
\operatorname{Max} P_{0}=\sum_{r=1}^{s} u_{r}, y_{r 0}+w \\
\text { sujeito a } \\
\sum_{i=1}^{m} v_{i}, x_{i 0}=1 \\
\sum_{r=1}^{n} u_{i}, y_{r j}-\sum_{i=1}^{m} v_{i}, x_{i j}+w \leq 0, \\
\operatorname{Min} P_{0}=\sum_{i=1}^{m} v_{i}, x_{i 0}+w \\
\text { sujeito a } \\
\sum_{r=1}^{s} u_{r} \cdot y_{r 0}=1 \\
-\sum_{r=1}^{n} v_{i}, x_{i j}+\sum_{i=1}^{m} u_{j}, y_{r j}-w \leq 0 \\
v_{i}, u_{i} \geq 0 ; w \in R .
\end{gathered}
$$

Os modelos DEA-CCR e DEA-BCC analisam a fronteira representada pelos melhores resultados e possíveis combinações destes. O DEA vai atribuir escores de eficiência entre 0 e 1 . O escore de 1 somente será atribuído a uma firma ou fazenda se a eficiência verificada for superior à eficiência calculada das demais firmas (JUBRAN, 2006). Aquelas DMUs que ficarem com escore menor que 1 serão consideradas ineficientes.

Dentre as classificações e aplicações dos modelos DEA, algumas opções devem ser escolhidas pelo pesquisador, com orientação aos inputs ou orientação aos outputs. O modelo orientado a outputs é utilizado quando se pretende obter o máximo nível de outputs mantendo os inputs fixos. Já o modelo orientado a inputs visa obter um menor uso de inputs dado o nível dos outputs.

Com efeito, o modelo utilizado neste estudo tem como orientação os inputs para o caso em que há K entradas e M saídas para cada uma das $\mathrm{N}$ empresas. Para a i-ésima DMUs, os dados de entrada e saída são representados pelos vetores de coluna $\mathrm{Xi}$ e $\mathrm{Yi}$, respectivamente. A matriz de entrada $\mathrm{KxN}, \mathrm{X}$, e a matriz de saída $\mathrm{MxN}, \mathrm{Y}$, representam os dados para todas as $\mathrm{N}$ DMUs em análise.

Nota-se que na fruticultura irrigada não se pode controlar as saídas, isto é, um aumento na quantidade de insumos não necessariamente resultará em um aumento proporcional na produção. Por isso, o modelo que melhor se adéqua para medir as 
eficiências de cada empresa ou fazenda é o modelo BCC, pois o mesmo trabalha com retornos variáveis de escala.

No entanto, nossa proposta no presente trabalho é medir a eficiência do uso da água na fruticultura irrigada. Isto é, medir a eficiência de um insumo individualmente. Para tanto, será necessário utilizar o modelo de eficiência de subvetor proposto por Fare, Grosskopf e Lovell (1994). Segundo o mesmo, no curto prazo alguns insumos podem ser fixos e, portanto, pode ser possível adquirir apenas um subvetor de entrada. Ou seja, alguns produtos podem ser produzidos com um insumo fixo, enquanto outros podem ser variáveis.

Para um melhor entendimento sobre a questão, torna-se necessário detalhar o que foi proposto por Fare, Grosskopf e Lovell (1994). Dessa forma, visa-se trabalhar com as medidas baseadas na eficiência de subvetor para os insumos, onde a eficiência é avaliada em relação a $L\{u \mid C, S\}$, sendo que $u$ representa o produto e $(\mathrm{C}, \mathrm{S})$ as entradas.

Assim, considera-se uma matriz de entradas $\mathrm{N}$ e uma matriz de saídas $\mathrm{M}$ e supondo que a matriz de entrada seja dividida, de modo que $\mathrm{N}=\left(\mathrm{N}^{\alpha}, \mathrm{N}^{a}\right)$, onde $\alpha \subseteq$ $\{1,2, \ldots ., N\}$ e ậ $=\{1,2, \ldots, N\} / \alpha$. Isso corresponde a escrever $x=\left\{X_{\alpha}, X_{a}\right)$, onde $X_{\alpha}$ é fixo e xậ é variável. Na amostra apresentada na seção seguinte, com foco nas lavouras irrigadas de manga e banana dos municípios do Vale do Açu, assume-se que todos os produtores têm os mesmos subvetores de insumos fixos e variáveis.

Para formar uma medida de eficiência radial do subvetor em relação às entradas $(C, S)$, calculamos:

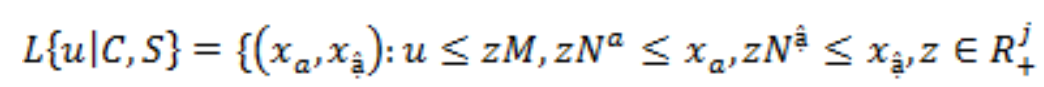

para $x_{\mathrm{a}}^{j} \geq 0$, temos:

$$
S F_{i}\left(u^{j}, x_{\alpha}^{j}, x_{\mathfrak{a} a}^{j} \mid C, S\right)=\min \left\{\lambda:\left(x_{\alpha}^{j}, x_{\mathfrak{a}}^{j}\right) \in L\left(u^{j} \mid C, S\right\}, j=1,2, \ldots \ldots J,\right.
$$

onde chamamos as medidas de subvetor das entradas (C, S) de eficiência técnica.

A seguir, usando programação linear, podemos particionar (6) para as entradas $(C, S)$ e medir eficiência técnica do subvetor de entrada $(C, S)$ para uma atividade j. Assim sendo, temos:

$$
\begin{gathered}
S F_{i}\left(u_{,}^{j}, x_{a}^{j}, x_{\mathrm{a} a}^{j} \mid C, s\right)=\min _{\lambda, z} \lambda \\
\text { sujeito a } \\
u^{j} \leq z M \\
z N^{a} \leq x_{a}^{j} \\
z N^{\mathrm{a}} \leq x_{\text {åa }}^{j}
\end{gathered}
$$




$$
\begin{gathered}
z \in R_{+}^{j} \\
\text { ou } \\
\min _{\lambda_{i} z} \lambda \\
\text { sujeito a } \\
u_{j m} \leq \sum_{j=1}^{J} z_{j} u_{j m}, m=1,2, \ldots, M_{,} \\
\sum_{j=1}^{J} z_{j} x_{j m} \leq x_{j n}, n \in a \\
\sum_{j=1}^{J} z_{j} x_{j m} \leq \lambda x_{j n}, n \in \text { âa, } \\
z_{j} \geq 0, j=1,2, \ldots \ldots, \ldots .
\end{gathered}
$$

Nesse caso, de acordo com Speelman et al. (2008), o modelo de eficiência de subvetor orientado aos inputs pode ser representado algebricamente por um Problema de Programação Linear (PPL). Desse modo, podemos medir a eficiência de um único insumo em vez de todos os vetores de entradas e saídas, conforme a seguinte equação (10):

$$
\begin{gathered}
\operatorname{Min}_{\theta_{i} \lambda} \theta^{k} \\
\text { sujeito a } \\
-\gamma_{i}+Y \lambda \geq 0 \\
\theta^{k} x_{i}^{k}-X^{k} \lambda \geq 0 \\
x_{i}^{n-k}-X^{n-k} \lambda \geq 0 \\
N_{1} \lambda=1 \\
\lambda \geq 0 .
\end{gathered}
$$

Onde $\theta^{k}$ é o escore de eficiência técnica do subvetor do input $k$ para 0 produtor i. Os termos $x_{i}^{n-k} e X^{n-k}$ na terceira restrição referem-se a $x_{i}$ e $X$ excluindo $k t h$ entradas (coluna), enquanto que na segunda restrição os termos $x^{k}{ }_{i}$ e $X^{k}$ incluem apenas as $k t h$ entradas. $\mathrm{N}_{1}$, por sua vez, é um vetor $\mathrm{N} \times 1$ de 1 (um) e $\lambda$ é um vetor $\mathrm{N} \times 1$ constante.

Para medir a eficiência técnica do modelo DEA CRS e VRS, foi utilizado o programa DEAP versão 2.1 (COELLI, 1996). Já o Sistema Geral de Modelagem Algébrica (General Algebraic Modeling System - GAMS) foi usado para medir a eficiência do subvetor, aplicando a metodologia proposta por Fare, Grosskopf e Lovell (1994). Finalmente, na busca de uma melhor visão das diferenças entre as medidas de eficiência obtidas pelos modelos DEA CRS, VRS e da eficiência do subvetor, foram utilizados dois testes estatísticos: o teste correlação de Pearson e o teste t de amostra pareada, apresentados na próxima subseção.

\section{Testes estatísticos dos modelos aplicados para analisar a eficiência do uso da água na fruticultura irrigada do Vale do Açu/RN}


Visando observar a robustez dos modelos utilizados, foram realizados dois testes estatísticos: o teste de correlação de Pearson e o teste $t$ de amostras pareadas. Nas Tabelas 1 e 2 são apresentadas as estatísticas de correlação entre a eficiência do subvetor para a água e a eficiência técnica geral dos produtores de manga e banana, o que ajuda a determinar a relação entre as duas medidas de eficiência.

No caso dos produtores de banana, percebe-se que há uma forte correlação positiva entre os resultados das eficiências técnicas gerais CRS e as eficiências do subvetor CRS e VRS para o uso da água. No entanto, para os produtores de manga, essa correlação, ainda que positiva, foi menos forte, como pode ser observado na Tabela 1. Isso indica que a eficiência de subvetor e as eficiências gerais capturam notoriamente diferentes aspectos da realidade estudada.

Tabela 1 - Teste de Correlação de Pearson: referente à correlação das eficiências dos produtores de manga do Vale do Açu, 2012-2015

\begin{tabular}{ccccc}
\hline & Subvetor CRS & Subvetor VRS & CRS Geral & VRS Geral \\
\hline Subvetor CRS & 1 & - & - & - \\
\hline Subvetor VRS & 0,7987 & 1 & - & - \\
\hline CRS Geral & 0,4740 & 0,3878 & 1 & - \\
\hline VRS Geral & 0,7368 & 0,6038 & 0,6785 & 1 \\
\hline
\end{tabular}

Fonte: Elaboração própria a partir do teste de correlação de Pearson (2018).

Tabela 2 - Teste de Correlação de Pearson: referente à correlação das eficiências dos produtores de banana do Vale do Açu, 2012-2015

\begin{tabular}{ccccc}
\hline & Subvetor CRS & Subvetor VRS & CRS Geral & VRS Geral \\
\hline Subvetor CRS & 1 & - & - & - \\
\hline Subvetor VRS & 0,8411 & 1 & - & - \\
\hline CRS Geral & 0,6932 & 0,7352 & 1 & - \\
\hline VRS Geral & 0,5631 & 0,5941 & 0,8149 & 1 \\
\hline
\end{tabular}

Fonte: Elaboração própria a partir do teste de correlação de Pearson (2018).

O teste $t$ de amostras pareadas foi aplicado também para analisar a igualdade entre as médias das eficiências do subvetor e das eficiências técnicas gerais. Analisando a Tabela 3, percebe-se que a hipótese de que as médias das eficiências são iguais foi aceita a um nível de significância de $95 \%$ para os produtores de manga.

Tabela 3 - Teste $t$ de amostras pareadas referente à diferença entre a eficiência técnica geral e a eficiência do subvetor dos produtores de manga do Vale do Açu, 2012-2015

\begin{tabular}{cccc}
\hline Variável & Média & Desvio Padrão & t - Estatístico \\
\hline Subvetor CRS & 0,5897 & 0,3334 & \multirow{2}{*}{$0,5736^{\star *}$} \\
\hline CRS Geral & 0,6216 & 0,2385 & \multirow{2}{*}{$1,4123^{\star *}$} \\
\hline Subvetor VRS & 0,7437 & 0,3053 & 0,2046 \\
\hline VRS Geral & 0,8067 &
\end{tabular}

Fonte: Elaboração própria a partir do teste t de amostras pareadas (2018).

Nota: ** indica um nível de significância de $95 \%$. 
No entanto, quando se observa a Tabela 4, o teste rejeita a hipótese nulo, de que as médias das eficiências são iguais. Isto é, a média das eficiências de subvetor e eficiência técnica gerais são diferentes.

Tabela 4 - Teste $t$ de amostras pareadas referente à diferença entre a eficiência técnica geral e a eficiência do subvetor dos produtores de banana do Vale do Açu, 2012-2015

\begin{tabular}{cccc}
\hline Variável & Média & Desvio Padrão & t - Estatístico \\
\hline Subvetor CRS & 0,4287 & 0,3138 & \multirow{2}{*}{$3,7737^{\star *}$} \\
\hline CRS Geral & 0,5151 & 0,2309 & \\
\hline Subvetor VRS & 0,5657 & 0,3462 & \multirow{2}{*}{$4,0810^{\star *}$} \\
\hline VRS Geral & 0,6806 & 0,1957 & \\
\hline
\end{tabular}

Fonte: Elaboração própria a partir do teste t de amostras pareadas (2018).

Nota: ** indica um nível de significância 95\%.

Os testes estatísticos realizados indicam, portanto, que os modelos adotados apresentam uma boa capacidade explicativa. A partir de sua aplicação foi possível identificar as características gerais dos sistemas produtivos irrigados no Vale do Açu/RN, focalizando a atenção no principal insumo da atividade, a água. Os principais resultados obtidos serão apresentados e discutidos na próxima seção.

\section{RESULTADOS E DISCUSSÃO}

Análise da eficiência do uso da água nas plantações irrigadas de manga no Vale do Açu

Dentre as frutíferas atualmente exploradas na microrregião do Vale do Açu, a manga aparece como uma das principais lavouras cultivadas e sua produção vem crescendo ano após ano. A exploração dessa fruta por meio da irrigação contribui para ascensão produtiva da cultura mesmo no período de seca. Como pode ser observado no Gráfico 1, nos anos de 2014 e 2015 o Vale do Açu respondeu por mais de 55\% da produção de manga do estado do Rio Grande do Norte.

Gráfico 1 - Evolução da produção de manga no Rio Grande do Norte e no Vale de Açu 2011 a 2015 (em toneladas)

\begin{tabular}{|c|c|c|c|c|c|}
\hline 50000 & & 38167 & 38115 & 42637 & 42194 \\
\hline 40000 & & & & & \\
\hline 30000 & 19134 & 18702 & 18702 & 23812 & 23812 \\
\hline 20000 & & & & & $\rightarrow$ \\
\hline 10000 & & & & & - \\
\hline 0 & & & & & - \\
\hline & 011 & 2012 & 2013 & 2014 & 2015 \\
\hline & & & 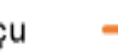 & & \\
\hline
\end{tabular}

Fonte: Elaboração a partir dos dados da PAM/IBGE (2018). 
Analisando a estrutura produtiva praticada na plantação de manga açuense e tomando como base a Tabela 5, pode-se observar uma grande diferença na receita total dos produtores por hectare. Essa desigualdade é resultante das diferentes estruturas dos fruticultores, uma vez que a amostra contemplou desde os produtores de pequeno porte aos produtores com sistemas irrigados mais sofisticados, pertencentes a esse cultivo.

Outra questão que deve ser considerada é o uso da água. Durante o período em análise, essa variável não apresentou nenhuma mudança nas estatísticas de um ano para o outro. Isso mostra que, mesmo com o advento da Grande Seca (20122015), a quantidade de água empregada nos cultivos de manga não foi alterada. Ou seja, não houve redução do volume de água empregada nas plantações.

Tabela 5 - Estatísticas descritivas das variáveis utilizadas na mensuração dos escores de eficiência técnica da fruticultura irrigada de manga por hectare no Vale do Açu/RN, 2012 a 2015

\begin{tabular}{c|c|c|c|c|c|c|c|c}
\hline \multirow{2}{*}{ Anos } & \multirow{2}{*}{ Estatísticas } & \multicolumn{7}{c}{ Variáveis } \\
\cline { 3 - 9 } 2012 & RT & CA & DF & DP & DMU & DME & DMO \\
\hline \multirow{4}{*}{2012} & Média & 13.615 & 20.286 & 1.201 & 212 & 3 & 650 & 4.094 \\
& Desvio Padrão & 7.660 & 11.098 & 1.166 & 184 & 10 & 755 & 1.972 \\
& Valor Máximo & 42.983 & 45.500 & 4.327 & 500 & 36 & 2.162 & 10.000 \\
& Valor Mínimo & 4.400 & 7.942 & 135 & 0 & 0 & 0 & 1.300 \\
\hline \multirow{4}{*}{2013} & Média & 14.196 & 20.286 & 1.414 & 238 & 2 & 769 & 4.322 \\
& Desvio Padrão & 7.337 & 11.098 & 1.219 & 285 & 8 & 913 & 1.949 \\
& Valor Máximo & 43.740 & 45.500 & 4.344 & 943 & 38 & 2.432 & 10.000 \\
& Valor Mínimo & 4.888 & 7.942 & 143 & 0 & 0 & 0 & 1.516 \\
\hline \multirow{4}{*}{2014} & Média & 15.001 & 20.286 & 1.576 & 238 & 2 & 732 & 4.605 \\
& Desvio Padrão & 7.441 & 11.098 & 1.346 & 295 & 9 & 831 & 2.103 \\
& Valor Máximo & 43.786 & 45.500 & 4.327 & 1.085 & 45 & 2.162 & 10.588 \\
& Valor Mínimo & 5.000 & 7.942 & 143 & 0 & 0 & 0 & 1.656 \\
\hline \multirow{4}{*}{2015} & Média & 16.951 & 20.286 & 1.660 & 256 & 1 & 949 & 4.939 \\
& Desvio Padrão & 7.624 & 11.098 & 1.389 & 310 & 8 & 1.238 & 2.430 \\
& Valor Máximo & 45.486 & 45.500 & 4.458 & 1.088 & 43 & 5.000 & 10.588 \\
& Valor Mínimo & 4.750 & 7.942 & 143 & 0 & 0 & 0 & 333 \\
\hline \multirow{2}{*}{2012} & Média & 14.941 & 20.286 & 1.463 & 236 & 2 & 775 & 4.490 \\
a & Desvio Padrão & 7.529 & 11.098 & 1.279 & 270 & 8 & 946 & 2.119 \\
2015 & Valor Máximo & 45.486 & 45.500 & 4.458 & 1.088 & 45 & 5.000 & 10.588 \\
& Valor Mínimo & 4.400 & 7.942 & 135 & 0 & 0 & 0 & 333 \\
\hline
\end{tabular}

Fonte: Elaboração própria a partir da pesquisa de campo (set./out. 2017).

Nota: $\mathrm{RT}=$ Receita total; $\mathrm{CA}=$ Consumo de água $/ \mathrm{m}^{3} ; \mathrm{DF}=$ Despesas com fertilizantes; $\mathrm{DP}=$ Despesas com pesticidas; $\mathrm{DMu}=$ Despesas com mudas; $\mathrm{DMe}=$ Despesas com mecanização; $\mathrm{DMo}=$ Despesas com mão de obra.

No entanto, é perceptível a diferenciação quanto aos outros insumos utilizados na produção, como as despesas com mão de obra e fertilizantes. Dentre os custos analisados, algumas variáveis tiveram registro zero (Tabela 5). Isso se deu pelo fato de uma parcela dos produtores não terem registrado no período despesas com mudas, pesticidas e mecanização. A ausência dessas despesas ocorre, principalmente, nas plantações de pequeno porte. $O$ baixo índice de pragas na 
região para cultura da manga contribui com a não utilização de pesticidas nas propriedades (GUERRA, 2012). Já a substituição da mecanização pelo serviço braçal, tanto para o roço quanto no suporte na colheita, é uma estratégia dos produtores para reduzir custos.

Quanto à eficiência produtiva, a Tabela 6 mostra o resumo dos escores da eficiência para os três modelos rodados: o DEA CRS, VRS e de subvetor para os produtores de manga. As classificações das eficiências dos produtores foram divididas por intervalos de classe para cada ano e para média do período em análise.

Com efeito, observando as distribuições dos escores de eficiência da média produtiva (2012-2015), o número de produtores eficientes atingiu $43 \%$ no modelo de subvetor VRS para uso da água. Paralelamente, o mesmo modelo mostra que muitos irrigantes têm problemas com a otimização da quantidade do líquido usado no plantio, haja vista que em média $34 \%$ dos produtores de manga não atingiram o escore 0,6 de eficiência.

Tabela 6 - Distribuição relativa dos produtores de manga irrigada do Vale do Açu de acordo com os intervalos de eficiência técnica do DEA e subvetor, 2012/2015

\begin{tabular}{|c|c|c|c|c|c|c|c|c|c|}
\hline \multirow{3}{*}{ Anos } & \multirow{3}{*}{$\begin{array}{l}\text { Medidas } \\
\text { de } \\
\text { eficiência }\end{array}$} & \multicolumn{4}{|c|}{ Eficiência do uso da água } & \multicolumn{4}{|c|}{ DEA } \\
\hline & & \multicolumn{2}{|c|}{ Subvetor CRS } & \multicolumn{2}{|c|}{ Subvetor VRS } & \multicolumn{2}{|l|}{ CRS } & \multicolumn{2}{|c|}{ VRS } \\
\hline & & Produtores & $\%$ & Produtores & $\%$ & Produtores & $\%$ & Produtores & $\%$ \\
\hline \multirow{7}{*}{2012} & $0,0 \dashv 0,2$ & 6 & $20 \%$ & 2 & $7 \%$ & 0 & $0 \%$ & 0 & $0 \%$ \\
\hline & $0,2-0,4$ & 6 & $20 \%$ & 3 & $10 \%$ & 10 & $33 \%$ & 0 & $0 \%$ \\
\hline & $0,4-0,6$ & 5 & $17 \%$ & 5 & $17 \%$ & 6 & $20 \%$ & 9 & $30 \%$ \\
\hline & $0,6-0,8$ & 3 & $10 \%$ & 0 & $0 \%$ & 7 & $23 \%$ & 2 & $7 \%$ \\
\hline & $0,8-1,0$ & 1 & $3 \%$ & 3 & $10 \%$ & 4 & $13 \%$ & 10 & $33 \%$ \\
\hline & 1,0 & 9 & $30 \%$ & 17 & $57 \%$ & 3 & $10 \%$ & 9 & $30 \%$ \\
\hline & $\begin{array}{l}\text { Total } \\
\text { geral }\end{array}$ & 30 & $100 \%$ & 30 & $100 \%$ & 30 & $100 \%$ & 30 & $100 \%$ \\
\hline \multirow{7}{*}{2013} & $0,0-0,2$ & 6 & $20 \%$ & 2 & $7 \%$ & 0 & $0 \%$ & 0 & $0 \%$ \\
\hline & $0,2-0,4$ & 6 & $20 \%$ & 6 & $20 \%$ & 9 & $30 \%$ & 0 & $0 \%$ \\
\hline & $0,4-0,6$ & 3 & $10 \%$ & 3 & $10 \%$ & 7 & $23 \%$ & 9 & $30 \%$ \\
\hline & $0,6-0,8$ & 2 & $7 \%$ & 2 & $7 \%$ & 4 & $13 \%$ & 3 & $10 \%$ \\
\hline & $0,8-1,0$ & 2 & $7 \%$ & 2 & $7 \%$ & 6 & $20 \%$ & 9 & $30 \%$ \\
\hline & 1,0 & 11 & $37 \%$ & 15 & $50 \%$ & 4 & $13 \%$ & 9 & $30 \%$ \\
\hline & $\begin{array}{l}\text { Total } \\
\text { geral }\end{array}$ & 30 & $100 \%$ & 30 & $100 \%$ & 30 & $100 \%$ & 30 & $100 \%$ \\
\hline \multirow{7}{*}{2014} & $0,0-0,2$ & 6 & $20 \%$ & 3 & $10 \%$ & 0 & $0 \%$ & 0 & $0 \%$ \\
\hline & $0,2-0,4$ & 6 & $20 \%$ & 4 & $13 \%$ & 4 & $13 \%$ & 0 & $0 \%$ \\
\hline & $0,4-0,6$ & 2 & $7 \%$ & 4 & $13 \%$ & 12 & $40 \%$ & 8 & $27 \%$ \\
\hline & $0,6-0,8$ & 1 & $3 \%$ & 1 & $3 \%$ & 3 & $10 \%$ & 3 & $10 \%$ \\
\hline & $0,8-1,0$ & 2 & $7 \%$ & 1 & $3 \%$ & 5 & $17 \%$ & 7 & $23 \%$ \\
\hline & 1,0 & 13 & $43 \%$ & 17 & $57 \%$ & 6 & $20 \%$ & 12 & $40 \%$ \\
\hline & $\begin{array}{l}\text { Total } \\
\text { geral }\end{array}$ & 30 & $100 \%$ & 30 & $100 \%$ & 30 & $100 \%$ & 30 & $100 \%$ \\
\hline
\end{tabular}




\begin{tabular}{c|c|c|c|c|c|c|c|c|c}
\hline & $0,0-0,2$ & 6 & $20 \%$ & 2 & $7 \%$ & 0 & $0 \%$ & 0 & $0 \%$ \\
& $0,2-0,4$ & 8 & $27 \%$ & 5 & $17 \%$ & 5 & $17 \%$ & 0 & $0 \%$ \\
2015 & $0,4-0,6$ & 3 & $10 \%$ & 4 & $13 \%$ & 10 & $33 \%$ & 4 & $13 \%$ \\
& $0,6-0,8$ & 2 & $7 \%$ & 2 & $7 \%$ & 6 & $20 \%$ & 8 & $27 \%$ \\
& $0,8-1,0$ & 1 & $3 \%$ & 1 & $3 \%$ & 6 & $20 \%$ & 8 & $27 \%$ \\
& 1,0 & 10 & $33 \%$ & 16 & $53 \%$ & 3 & $10 \%$ & 10 & $33 \%$ \\
\hline & Total & 30 & $100 \%$ & 30 & $100 \%$ & 30 & $100 \%$ & 30 & $100 \%$ \\
\hline & geral & & & & & & \\
& $0,0-0,2$ & 0 & $0 \%$ & 2 & $7 \%$ & 0 & $0 \%$ & 0 & $0 \%$ \\
2012 & $0,2-0,4$ & 0 & $0 \%$ & 3 & $10 \%$ & 4 & $13 \%$ & 0 & $0 \%$ \\
$a$ & $0,4-0,6$ & 9 & $30 \%$ & 5 & $17 \%$ & 12 & $40 \%$ & 9 & $30 \%$ \\
2015 & $0,6-0,8$ & 3 & $10 \%$ & 3 & $10 \%$ & 4 & $13 \%$ & 3 & $10 \%$ \\
& $0,8-1,0$ & 12 & $40 \%$ & 4 & $13 \%$ & 9 & $30 \%$ & 12 & $40 \%$ \\
& 1,0 & 6 & $20 \%$ & 13 & $43 \%$ & 1 & $3 \%$ & 6 & $20 \%$ \\
\hline & Total & 30 & $100 \%$ & 30 & $100 \%$ & 30 & $100 \%$ & 30 & $100 \%$ \\
\hline
\end{tabular}

Fonte: Elaboração própria a partir da pesquisa de campo (set./out. 2017).

Ainda na Tabela 6, analisando a eficiência média para o período de 2012 a 2015, verifica-se que o número de produtores da amostra que tiveram níveis de eficiência plena no modelo subvetor CRS foi muito baixo: apenas seis produtores foram eficientes. Sob as condições analisadas, cerca de $3 \%$ e $20 \%$ dos fruticultores foram identificadas como tecnicamente eficientes sob a especificação DEA CRS e VRS, respectivamente.

Em resumo, os irrigantes das lavouras de manga ineficientes atingem 57\%, quando se comparado na média para o período estudado, contabilizando 17 produtores ineficientes. Essas diferenças entre as medidas de eficiência dos modelos CRS e do VRS indicam que muitos produtores de manga não operam numa escala eficiente.

Nota-se também que existe uma acentuada diferença no quantitativo de produtores eficientes entre os modelos DEA CRS e VRS, sinalizando que os produtores de manga do Vale do Açu apresentam problemas com a escala produtiva, operando em escalas ineficientes. Isso significa que um ajuste na escala de operação poderia melhorar a eficiência. Conclusão semelhante foi constatada no estudo de Pinheiro (2010), que procurou analisar os custos dos produtores do Projeto Baixo Açu, apontando que as fazendas da região apresentam índice de eficiência muito baixo, variando entre 0,2 a 0,6. Ou seja, os produtores estudados, além de serem ineficientes no uso da água, apresentam problemas de otimização no emprego dos demais insumos.

Outro resultado analisado na presente pesquisa foi a questão da eficiência no consumo de água no cultivo da banana. Esse tipo de plantação requer um maior volume de água e tem maior quantidade de produtores na região do Vale do Açu. Os 
índices de eficiência para esses fruticultores são ainda menores, como se pode observar no próximo tópico.

\section{Análise da eficiência do uso da água nas plantações irrigadas de banana do Vale do Açu}

A banana é a principal fruta produzida no Vale do Açu, servindo como fonte de riqueza para empresas nacionais, estrangeiras e agricultores familiares. No ano de 2015, período considerado crítico pela seca que assolava o Nordeste, o Vale do Açu foi responsável pela produção de 86.398 toneladas da referida fruta. Isso equivale a 56\% da produção do RN, como mostra o Gráfico 2. Note-se que de 2011 a 2015 a produção manteve-se e apresentou um ligeiro crescimento, sinalizando que a estiagem não afetou a atividade.

Gráfico 2 - Evolução da produção de banana no Vale de Açu de 2011 a 2015 (em toneladas)

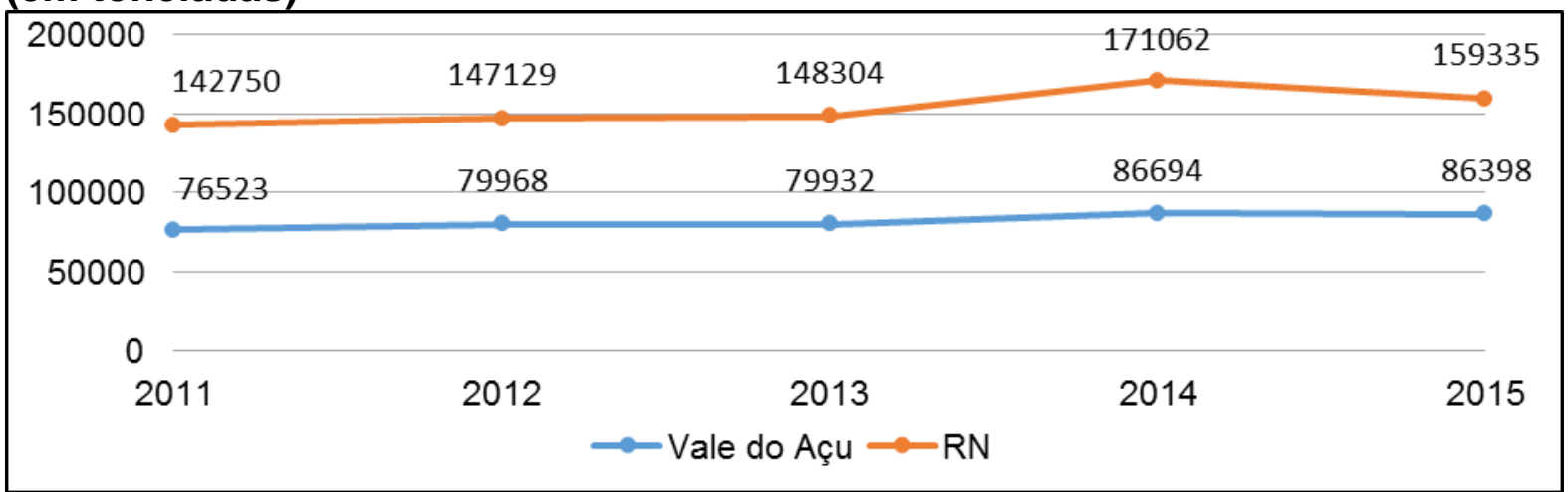

Fonte: Elaboração a partir dos dados da PAM/IBGE (2018).

No cultivo da banana, a demanda por água é bem superior se comparada a outras frutas, como por exemplo a manga. Na Tabela 7, observa-se que a média de consumo de água é de $27.384 \mathrm{~m}^{3}$, valor $26 \%$ maior que no cultivo da manga. Essa alta demanda por água se dá devido à planta ter uma produção de folhas de grande dimensão, por isso necessita de mais água. Já as despesas com fertilizantes e mão de obra apresentam-se como os maiores gastos dos produtores de banana por hectare. No ano de 2015, por exemplo, os gastos médios por hectare com esses insumos chegaram a $R \$ 1.745,00$ e $R \$ 3.165,00$, respectivamente, somando $96 \%$ das despesas dos agricultores.

Adicionalmente, vale registrar que alguns produtores apresentaram despesa zero com pesticidas, mudas e mecanização para a produção da banana, sendo uma 
prática comum entre os pequenos produtores em busca de reduzir custos (Tabela 7). Para isso, extraem as mudas dos seus próprios plantios, muitas vezes sem técnica adequada para identificação dos melhores brotos, e utilizam-se da prática do roço.

Tabela 7 - Estatísticas descritivas das variáveis utilizadas na mensuração dos escores de eficiência técnica da fruticultura irrigada de banana por hectare no Vale do Açu/RN, 2012 a 2015.

\begin{tabular}{|c|c|c|c|c|c|c|c|c|}
\hline \multirow{2}{*}{ Anos } & \multirow{2}{*}{ Estatísticas } & \multicolumn{7}{|c|}{ Variáveis } \\
\hline & & RT & CA & DF & DP & DMu & DMe & DMo \\
\hline \multirow{4}{*}{2012} & Média & 20.560 & 27.384 & 1.432 & 77 & 45 & 107 & 2.644 \\
\hline & Desvio Padrão & 9.922 & 12.157 & 1.484 & 93 & 159 & 882 & 1.112 \\
\hline & Valor Máximo & 46.920 & 54.600 & 5.884 & 297 & 710 & 416 & 6.158 \\
\hline & Valor Mínimo & 5.760 & 9.100 & 36 & 0 & 0 & 0 & 647 \\
\hline \multirow{4}{*}{2013} & Média & 22.263 & 27.384 & 1.514 & 77 & 32 & 75 & 2.846 \\
\hline & Desvio Padrão & 10.744 & 12.157 & 1.589 & 93 & 133 & 75 & 1.140 \\
\hline & Valor Máximo & 51.260 & 54.600 & 6.404 & 297 & 710 & 274 & 6.240 \\
\hline & Valor Mínimo & 4.368 & 9.100 & 36 & 0 & 0 & 0 & 705 \\
\hline \multirow{4}{*}{2014} & Média & 22.991 & 27.384 & 1.520 & 77 & 32 & 99 & 2.925 \\
\hline & Desvio Padrão & 11.369 & 12.157 & 1.586 & 94 & 133 & 100 & 1.173 \\
\hline & Valor Máximo & 57.947 & 54.600 & 6.404 & 297 & 710 & 402 & 6.568 \\
\hline & Valor Mínimo & 5.408 & 9.100 & 28 & 0 & 0 & 0 & 752 \\
\hline \multirow{4}{*}{2015} & Média & 22.431 & 27.384 & 1.578 & 78 & 39 & 85 & 3.166 \\
\hline & Desvio Padrão & 10.68 & 12.157 & 1.667 & 94 & 139 & 94 & 1.339 \\
\hline & Valor Máximo & 57.600 & 54.600 & 6.500 & 27 & 710 & 370 & 7.400 \\
\hline & Valor Mínimo & 5.760 & 9.100 & 28 & 0 & 0 & 0 & 819 \\
\hline \multirow{4}{*}{$\begin{array}{c}2012 \\
a \\
2015\end{array}$} & Média & 22.789 & 27.384 & 1.564 & 81 & 37 & 94 & 3.026 \\
\hline & Desvio Padrão & 10.299 & 12.157 & 1.579 & 103 & 141 & 105 & 1.578 \\
\hline & Valor Máximo & 57.947 & 54.600 & 6.500 & 842 & 710 & 416 & 7.400 \\
\hline & Valor Mínimo & 5.408 & 9.100 & 36 & 0 & 0 & 0 & 1.371 \\
\hline
\end{tabular}

Fonte: Elaboração própria a partir da pesquisa de campo (set./out. 2017).

Nota: $\mathrm{RT}=$ Receita total; $\mathrm{CA}=$ Consumo de água $/ \mathrm{m}^{3} ; \mathrm{DF}=$ Despesas com fertilizantes; $\mathrm{DP}=$ Despesas com pesticidas; $\mathrm{DMu}=$ Despesas com mudas; $\mathrm{DMe}=$ Despesas com mecanização; $\mathrm{DMo}=$ Despesas com mão de obra

No que diz respeito aos índices de eficiência para o consumo de água dos produtores de banana, pode-se observar na Tabela 8 um baixo número de fazendas totalmente eficientes. No ano de 2014, onde os resultados obtidos foram melhores, a eficiência de subvetor da água aponta que o número de produtores eficientes no cultivo de banana foi de $27 \%$ e $38 \%$ com especificação CRS e VRS, respectivamente. Para os demais anos, os quantitativos de fruticultores eficientes foram menores.

Ainda analisando os escores de eficiência com base na Tabela 8, para o modelo DEA com retorno constante e variáveis de escala, é perceptivo uma maior concentração de produtores com escore de eficiência entre 0,2 a 0,8 no modelo DEA CRS. Já no DEA VRS, essa concentração passa para 0,4 a 1. Essa mudança nos escores de eficiência de um modelo para o outro é provocada por critérios de avaliação dos modelos, uma vez que cada um considera diferentes tecnologias de 
referência. Esses resultados apontam, resumidamente, que muitos produtores de banana não operam numa escala eficiente.

Tabela 8 - Distribuição relativa dos produtores de banana irrigada do Vale do Açu de acordo com os intervalos de eficiência técnica do DEA e subvetor, 2012 a 2015

\begin{tabular}{|c|c|c|c|c|c|c|c|c|c|}
\hline \multirow{3}{*}{ Anos } & \multirow{3}{*}{$\begin{array}{l}\text { Medidas } \\
\text { de } \\
\text { eficiência }\end{array}$} & \multicolumn{4}{|c|}{ Eficiência do uso da água } & \multicolumn{4}{|c|}{ DEA } \\
\hline & & \multicolumn{2}{|c|}{ Subvetor CRS } & \multicolumn{2}{|c|}{ Subvetor VRS } & \multicolumn{2}{|c|}{ CRS } & \multicolumn{2}{|l|}{ VRS } \\
\hline & & Produtores & $\%$ & Produtores & $\%$ & Produtores & $\%$ & Produtores & $\%$ \\
\hline \multirow{7}{*}{2012} & \begin{tabular}{l|l}
$0,0-0,2$
\end{tabular} & 30 & $31 \%$ & 20 & $20 \%$ & 6 & $6 \%$ & 0 & $0 \%$ \\
\hline & $0,2-0,4$ & 29 & $30 \%$ & 29 & $30 \%$ & 28 & $29 \%$ & 9 & $9 \%$ \\
\hline & $0,4-0,6$ & 9 & $9 \%$ & 9 & $9 \%$ & 22 & $22 \%$ & 32 & $33 \%$ \\
\hline & $0,6-0,8$ & 4 & $4 \%$ & 3 & $3 \%$ & 17 & $17 \%$ & 24 & $24 \%$ \\
\hline & $0,8-1,0$ & 2 & $2 \%$ & 5 & $5 \%$ & 17 & $17 \%$ & 20 & $20 \%$ \\
\hline & 1,0 & 24 & $24 \%$ & 32 & $33 \%$ & 8 & $8 \%$ & 13 & $13 \%$ \\
\hline & Total Geral & 98 & $100 \%$ & 98 & $100 \%$ & 98 & $100 \%$ & 98 & $100 \%$ \\
\hline \multirow{7}{*}{2013} & $0,0-0,2$ & 35 & $36 \%$ & 23 & $23 \%$ & 4 & $4 \%$ & 0 & $0 \%$ \\
\hline & $0,2-0,4$ & 28 & $29 \%$ & 26 & $27 \%$ & 26 & $27 \%$ & 9 & $9 \%$ \\
\hline & $0,4-0,6$ & 9 & $9 \%$ & 8 & $8 \%$ & 29 & $30 \%$ & 24 & $24 \%$ \\
\hline & $0,6-0,8$ & 7 & $7 \%$ & 6 & $6 \%$ & 19 & $19 \%$ & 33 & $34 \%$ \\
\hline & $0,8-1,0$ & 3 & $3 \%$ & 4 & $4 \%$ & 8 & $8 \%$ & 15 & $15 \%$ \\
\hline & 1,0 & 16 & $16 \%$ & 31 & $32 \%$ & 12 & $12 \%$ & 17 & $17 \%$ \\
\hline & Total Geral & 98 & $100 \%$ & 98 & $100 \%$ & 98 & $100 \%$ & 98 & $100 \%$ \\
\hline \multirow{7}{*}{2014} & $0,0-0,2$ & 36 & $37 \%$ & 20 & $20 \%$ & 10 & $10 \%$ & 0 & $0 \%$ \\
\hline & $0,2-0,4$ & 22 & $22 \%$ & 25 & $26 \%$ & 29 & $30 \%$ & 9 & $9 \%$ \\
\hline & $0,4-0,6$ & 5 & $5 \%$ & 8 & $8 \%$ & 29 & $30 \%$ & 36 & $37 \%$ \\
\hline & $0,6-0,8$ & 7 & $7 \%$ & 5 & $5 \%$ & 20 & $20 \%$ & 27 & $28 \%$ \\
\hline & $0,8-1,0$ & 2 & $2 \%$ & 3 & $3 \%$ & 5 & $5 \%$ & 15 & $15 \%$ \\
\hline & 1,0 & 26 & $27 \%$ & 37 & $38 \%$ & 5 & $5 \%$ & 11 & $11 \%$ \\
\hline & Total Geral & 98 & $100 \%$ & 98 & $100 \%$ & 98 & $100 \%$ & 98 & $100 \%$ \\
\hline \multirow{7}{*}{2015} & $0,0-0,2$ & 43 & $44 \%$ & 21 & $21 \%$ & 10 & $10 \%$ & 0 & $0 \%$ \\
\hline & $0,2-0,4$ & 25 & $26 \%$ & 23 & $23 \%$ & 32 & $33 \%$ & 10 & $10 \%$ \\
\hline & $0,4-0,6$ & 5 & $5 \%$ & 8 & $8 \%$ & 30 & $31 \%$ & 36 & $37 \%$ \\
\hline & $0,6-0,8$ & 9 & $9 \%$ & 7 & $7 \%$ & 16 & $16 \%$ & 26 & $27 \%$ \\
\hline & $0,8-1,0$ & 3 & $3 \%$ & 4 & $4 \%$ & 5 & $5 \%$ & 16 & $16 \%$ \\
\hline & 1,0 & 13 & $13 \%$ & 35 & $36 \%$ & 5 & $5 \%$ & 10 & $10 \%$ \\
\hline & Total Geral & 98 & $100 \%$ & 98 & $100 \%$ & 98 & $100 \%$ & 98 & $100 \%$ \\
\hline \multirow{7}{*}{$\begin{array}{c}2012 \\
a \\
2015\end{array}$} & $0,0-0,2$ & 32 & $33 \%$ & 19 & $20 \%$ & 7 & $7 \%$ & 0 & $0 \%$ \\
\hline & $0,2-0,4$ & 24 & $25 \%$ & 23 & $24 \%$ & 30 & $31 \%$ & 4 & $4 \%$ \\
\hline & $0,4-0,6$ & 12 & $12 \%$ & 13 & $13 \%$ & 30 & $31 \%$ & 34 & $35 \%$ \\
\hline & $0,6-0,8$ & 13 & $13 \%$ & 8 & $8 \%$ & 16 & $16 \%$ & 30 & $31 \%$ \\
\hline & $0,8-1,0$ & 7 & $7 \%$ & 7 & $7 \%$ & 12 & $12 \%$ & 24 & $24 \%$ \\
\hline & 1,0 & 10 & $10 \%$ & 28 & $28 \%$ & 3 & $3 \%$ & 6 & $6 \%$ \\
\hline & Total Geral & 98 & $100 \%$ & 98 & $100 \%$ & 98 & $100 \%$ & 98 & $100 \%$ \\
\hline
\end{tabular}

Fonte: Elaboração própria a partir da pesquisa de campo (set./out. 2017).

Observando o consumo médio da água no cultivo da banana, o modelo de subvetor VRS apresentou escores de eficiência muito baixos se comparado à eficiência ano a ano. O quantitativo de produtores eficientes na média chega a $28 \%$ dos entrevistados. Isso significa que 71 irrigantes foram considerados ineficientes, resultado equivalente a $72 \%$ da amostra pesquisada, indicando que parcela dos 
produtores de banana utiliza mecanismos de irrigação com tecnologia deficitária, gerando elevado desperdício de água.

Um fator que contribui para explicar a elevada ineficiência no uso dos recursos hídricos no Vale do Açu é que os irrigantes não pagam nenhum valor monetário pela quantidade de água usada nas lavouras, mas somente custeiam a energia que é usada pelos motores de bombeamento e pelos implementos de irrigação. Assim, os produtores não assimilam os princípios básicos da agricultura irrigada eficiente, adotando comportamentos ineficientes.

Os resultados apresentados apontam também que não foram registradas modificações nos manejos dos sistemas de irrigação dos produtores durante a Grande Seca. O manejo inadequado da água é tema preocupante, em especial em regiões que sofrem com escassez de recursos hídricos, como é o caso da área estudada. Por conta disso, é preciso implementar políticas públicas para alterar o cenário apresentado, especialmente disponibilizando assistência técnica especializada aos produtores.

\section{CONSIDERAÇÕES FINAIS}

O presente estudo teve por objetivo analisar a eficiência do uso da água na fruticultura irrigada no Vale do Açu/RN, nos cultivos da manga e banana. Parte-se do pressuposto de que o uso eficiente da água na agricultura irrigada, tanto na perspectiva econômica, quanto na ambiental e social, torna-se algo imprescindível, pois auxiliará no processo de montagem de políticas públicas voltadas para um modelo de agricultura que faz o melhor uso dos recursos hídricos no semiárido nordestino.

A metodologia utilizada permitiu encontrar o escore da eficiência técnica de cada produtor, possibilitando a classificação dos eficientes e ineficientes. Aqueles produtores que atingiram escores 1 (um) foram considerados eficientes, já que se encontravam na fronteira. E aqueles que não atingiram escores de 1(um) foram ineficientes.

Os agricultores da área pesquisada não alcançaram níveis de eficiência satisfatório, tanto na eficiência técnica, quanto na eficiência de subvetor da água. No cultivo da manga, na média de 2012 a 2015, apenas 13 produtores foram eficientes no uso da água, considerando os retornos variáveis de escala. Já no cultivo banana esses números caíram mais ainda proporcionalmente. Foram pesquisados 98 produtores de banana, dos quais 28 foram eficientes no uso da água, o que 
corresponde $28 \%$ da amostra. No geral, o número de produtores ineficientes no uso da água foi considerado alto nas duas culturas (manga e banana), sinalizando o desperdício desse valioso recurso natural em plena seca.

Observando as eficiências da média produtiva, os resultados indicam que há espaço substancial para reduzir o uso da água nas plantações usando a tecnologia existente, sem comprometer a produtividade das áreas irrigadas. Desta forma, podese reduzir a pressão sobre os recursos hídricos ou realocar uma fração da água da irrigação para outras finalidades econômicas.

Para melhorar o desempenho produtivo e reduzir o consumo de água, os produtores precisam adequar-se aos manejos e à aplicação de água no momento correto e na quantidade demandada pela cultura. Para isso, a disponibilização de assistência técnica e incentivos financeiros poderia ajudar a introduzir aperfeiçoamentos nos sistemas irrigados, contribuindo para que os produtores possam melhorar sua produtividade e eficiência no manejo das culturas.

Dessa forma, a análise da eficiência do subvetor para a água fornece informações importantes para a tomada de decisões, sejam elas coletivas ou individuais, e aos serviços de extensão rural sobre como focalizar os esforços para melhorar a eficiência do uso da água. Com a análise sobre a eficiência do subvetor, as entidades públicas podem também trabalhar os serviços de extensão e incentivar os agricultores a selecionar culturas com maior lucro por $\mathrm{m}^{3}$ de água utilizada.

Para avançar na discussão relativa ao tema, estudos posteriores podem ser desenvolvidos tendo como foco a eficiência alocativa e econômica. Assim, pode-se determinar o alcance das melhorias de produção. Da mesma forma, novas pesquisas podem ser desenvolvidas buscando mensurar o valor monetário da água utilizada nos perímetros irrigados, tendo em vista que os produtores não pagam pelo consumo deste recurso natural e sim pela energia que é usada na sua captação nas fontes disponíveis.

\section{REFERÊNCIAS}

ALBANO, G. P.; SÁ, A. J. Vale do Açu-RN: a passagem do extrativismo da carnaúba para a monocultura de banana. Revista de Geografia. Recife/PE, v. 26, n. 3, p. 632, 2009.

ALVES, V. E. L.; AQUINO, J. R.; SILVA FILHO, R. I. A modernização da fruticultura irrigada e seus impactos socioeconômicos e ambientais no Vale do Açu/RN. Revista Geolnterações. Assú/RN, v. 2, n. 1, p. 35-56, 2018. 
ANA. Conjuntura dos recursos hídricos no Brasil 2017. Brasília/DF: ANA, 2017. Disponível em: <http://www.snirh.gov.br/portal/snirh/centrais-de-conteudos/conjuntur a-dos-recursos-hidricos/relatorio-conjuntura-2017>. Acesso em: 20 jun. 2019.

BANKER, R. D.; CHARNES, A.; COOPER, W. W. Some models for estimating technical and scale inefficiencies in data envelopment analysis. Management Science. v. 30, n. 9, p. 1078-1092, 1984.

CHARNES, A.; COOPER, W. W.; RHODES, E. Measurement the efficiency of Decision Marking Units. European Journal of Operational Research. Amsterdam. v. 2, n. 6, p. 429-444, 1978.

CHEBIL, A.; FRIJA, A.; ABDELKAFI, B. Irrigation water use efficiency in collective irrigated schemes of Tunisia: determinants and potential irrigation cost reduction. Agricultural Economics Review. v. 13, n. 1, p. 39-48, 2012.

COELLI, T. A guide to DEAP version 2.1: a data envelopment analysis (computer) program. Centre for Efficiency and Productivity Analysis. Australia: University of New England, Australia, 1996.

COELLI, T.; RAHMAN, S.; THIRTLE, C. Technical, allocative, cost and scale efficiencies in Bangladesh rice cultivation: a non-parametric approach. Journal of Agricultural Economics. v. 53, n. 3, p. 607-626, 2002.

DE KOEIJER, T. J. et al. Measuring agricultural sustainability in terms of efficiency: the case of Dutch sugar beet growers. Journal of environmental management. $v$. 66, n. 1, p. 9-17, 2002.

DHUNGANA, B. R.; NUTHALL, P. L.; NARTEA, G. V. Measuring the economic inefficiency of Nepalese rice farms using data envelopment analysis. Australian Journal of Agricultural and Resource Economics. v. 48, n. 2, p. 347-369, 2004.

FARE, R.; GROSSKOPF, S.; LOVELL, C. K. Production frontiers. Cambridge: Cambridge University Press, 1994.

FARRELL, M, J. The measurement of productive efficiency. Journal of the Royal Statistical Society. v. 120, n. 3, p. 253-281, 1957.

FRANÇA, J. M. F.; MORENO, J. C. Uma reflexão sobre os impactos causados pela seca no Rio Grande do Norte de 2012 a 2016. Parceria Estratégicas. Brasília /DF. v. 22, n. 44, p. 213-232, jan./jun. 2017.

GIL, A. C. Métodos e técnicas de pesquisa social. 6. ed. São Paulo: Atlas, 2008.

GUERRA, A. G. Prospecção tecnológica nas cadeias produtivas das principais fruteiras: estudo de caso no Rio Grande do Norte. Joinville/SC: Clube dos Autores, 2012.

IBGE. Censo agropecuário. 2006. Rio de Janeiro/RJ: IBGE, 2012. Disponível em: <http://www.ibge.gov.br>. Acesso em: 10 ago. 2017. 
IBGE. Área da unidade territorial. 2018. Rio de Janeiro/RJ: IBGE, 2018. Disponível em: <http://cidades.ibge.gov.br/brasil/sintese/rn?indicadores=29167>. Acesso em: 15 jun. 2019.

JUBRAN, A. J. Modelo de análise de eficiência na administração pública: estudo aplicado às prefeituras brasileiras usando a análise envoltória de dados. São Paulo. 2006. 226f. Tese (Doutorado em Sistemas Eletrônicos) - Escola Politécnica, Universidade de São Paulo. São Paulo, 2006.

MARIANO, E. B. Sistematização e comparação de técnicas, modelos e perspectivas não-paramétricas de análise de eficiência produtiva. 2008. Dissertação (Mestrado em Engenharia de Produção) - Escola de Engenharia de São Carlos, Universidade de São Paulo, São Carlos, 2008.

MARIANO, J.; PINHEIRO, G. M. T. L. Eficiência técnica da agricultura familiar no projeto de irrigação do Baixo Açu (RN). Revista Econômica do Nordeste. Fortaleza/CE. v. 40, n. 2, p. 283-296, 2009.

MARIANO, J.; SAMPAIO, Y. A eficiência técnica dos colonos nos perímetros irrigados em Petrolina/Juazeiro: uma análise de modelos de fronteiras de produção. Revista Econômica do Nordeste. Fortaleza/CE, v. 33, n. 2, p. 159-179, 2002.

MARTINS, N.; JULIÃO, V. Corte de água para perímetro afetará 1,5 mil irrigantes. Tribuna do Norte. Natal, 2015. Disponível em: <http://www.tribunadonorte.com.br>. Acesso em: 20 maio 2019.

NUNES, E., M.; ORTEGA, A. C.; GODEIRO, K. F. Desenvolvimento rural em áreas de intervenção estatal do Nordeste: o caso do projeto de irrigação Baixo-Açu. Revista Econômica do Nordeste. Fortaleza/CE, v. 38, n. 3, p. 446-465, 2007.

PAM/IBGE. Pesquisa Agrícola Municipal. Rio de Janeiro: IBGE, 2018. Disponível em: <http://www.ibge.gov.br/estatisticas-novoportal/economicas/agricultura-epecuaria/9117-producao-agricola-municipal-culturas-permanentes.html?edicao= 9118\&t=>. Acesso em: 5 jun. 2019.

PINHEIRO, G. M. T. L. A fruticultura irrigada de pequenos produtores no BaixoAçu: uma análise da eficiência de custo. Natal. 2010. 60f. Dissertação (Mestrado em Economia) -Universidade Federal do Rio Grande do Norte (UFRN), Natal/RN, 2010.

SEMARH. Boletim diário de monitoramento hidrometeorológico. Natal/RN, 2015. Disponível em: <http://adcon.rn.gov.br>. Acesso em: 30 jun. 2019.

SOUZA, E. M.; AQUINO, J. R. A grande seca e seus efeitos na produção agropecuária do Rio Grande do Norte (2012-2016). Revista GeoNordeste. São Cristóvão/SE, ano XXIX, n. 2, p. 174-195, 2018.

SPEELMAN, S. et al.. A measure for the efficiency of water use and its determinants: a case study of small-scale irrigation schemes in North-West Province, South Africa. Agricultural systems. v. 98, n. 1, p. 31-39, 2008.

TUPY, O.; YAMAGUCHI, L. C. T. Eficiência e produtividade: conceitos e medição. Agricultura em São Paulo, v. 45, p. 39-51, 1998. 
UNESCO. The United Nations world water development report 2016: water and jobs. Paris, 2016.

WADUD, A.; WHITE, B. Farm household efficiency in Bangladesh: a comparison of stochastic frontier and DEA methods. Applied economics. v. 32, n. 13, p. 16651673, 2000.

\section{NOTAS DE AUTOR}

\section{CONTRIBUIÇÃO DE AUTORIA}

Rosival Gomes de Brito - Concepção, coleta de dados, análise de dados, elaboração do manuscrito, revisão e aprovação da versão final do trabalho.

Zezineto Mendes de Oliveira - Concepção, elaboração do manuscrito, revisão e aprovação da versão final do trabalho.

Joacir Rufino de Aquino - Concepção, elaboração do manuscrito, revisão e aprovação da versão final do trabalho.

\section{FINANCIAMENTO}

Não se aplica.

\section{CONSENTIMENTO DE USO DE IMAGEM}

Não se aplica.

APROVAÇÃO DE COMITÊ DE ÉTICA EM PESQUISA

Não se aplica.

\section{CONFLITO DE INTERESSES}

Não se aplica.

\section{LICENÇA DE USO}

Este artigo está licenciado sob a Licença Creative Commons CC-BY. Com essa licença você pode compartilhar, adaptar, criar para qualquer fim, desde que atribua a autoria da obra.

\section{HISTÓRICO}

Recebido em: 09-08-2019

Aprovado em: 21-01-2020 